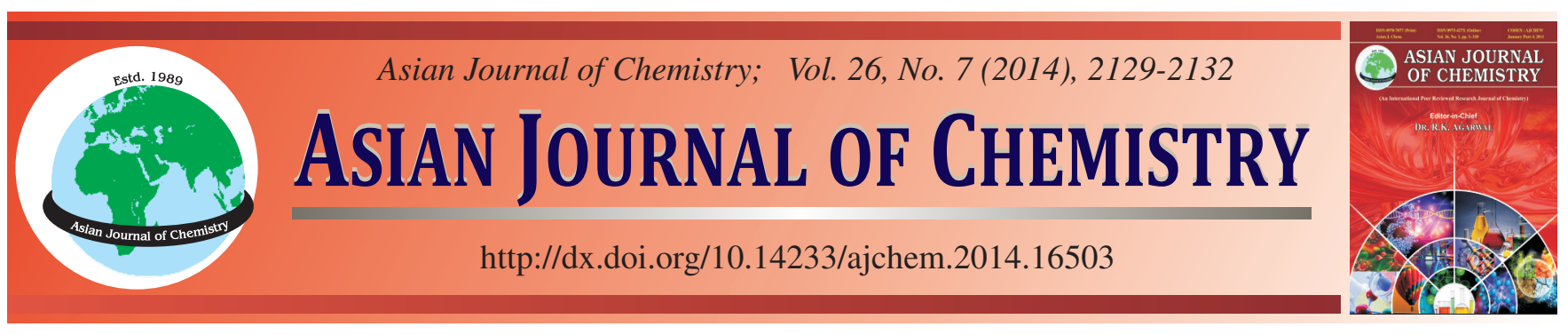

\title{
Preparation of ZnO Nanoparticles Under Ultrasonic Irradiation and Photocatalytic Performance of ZnO Nanoparticles Multilayer Films
}

\author{
Hae Soo Park and Weon BaE Ko*
}

Department of Chemistry, Sahmyook University, Seoul 139-742, Republic of Korea

*Corresponding author: Fax: +82 2 9795318; Tel: +82 2 33991700; E-mail: kowb@syu.ac.kr

\begin{abstract}
Zinc oxide nanoparticles were synthesized by the reaction of an aqueous-alcoholic solution containing zinc nitrate hexahydrate and sodium hydroxide under ultrasonic irradiation at room temperature. The crystallinity, morphology and optical property of ZnO nanoparticles were examined by X-ray diffraction, scanning electron microscopy, transmission electron microscopy and UV-visible spectrophotometer. Zinc oxide nanoparticles multilayer films were prepared dipping glass slide, which had been cleaned with a piranha solution, into a $\mathrm{ZnO}$ solution by ultrasonic irradiation. The $\mathrm{ZnO}$ nanoparticles multilayer films were evaluated as a photocatalyst in the photocatalytic degradation of organic dyes, such as methylene blue, methyl orange and rhodamine B, under ultraviolet light at $254 \mathrm{~nm}$.
\end{abstract}

Keywords: Zinc oxide nanoparticles, Multilayer films, Photocatalytic activity, Organic dyes, UV-visible spectrophotometer.

\section{INTRODUCTION}

Zinc oxide is an interesting semiconductor material with wide band gap of $3.37 \mathrm{eV}$ and high excitonic binding energy of $60 \mathrm{meV}^{1,2}$. Zinc oxide nanoparticles are promising materials in areas, such as ultraviolet lasers, light-emitting diodes, flat panel displays, photodetectors, gas sensors, catalysis, $\mathrm{pH}$ meters, solar cells and nanogenerators, because they are non-toxic and have unique chemical properties ${ }^{3-7}$. Among metal oxides, titanium dioxide is the most popular photocatalyst for the removal of organic molecules in water ${ }^{8}$. On the other hand, $\mathrm{ZnO}$ is suitable as an alternative photocatalyst for the degradation of several environmental contaminants, such as organic dyes, owing to its high photosensitivity, stability and similar band gap compared to $\mathrm{TiO}_{2}$ nanomaterials 9 .

The self-assembly and organization of metal nanoparticles in thin films has attracted considerable attention because of their potential applications in molecular and nano devices ${ }^{10}$. The self-assembly of nanoparticles is based on the electrostatic attraction between the adsorbed monolayers of nanoparticles and oppositely charged linker molecules ${ }^{11,12}$. Zinc oxide nanoparticles multilayer films can be formed in many ways, such as electron beam evaporation, sol-gel, sputtering, molecular epitaxy, chemical vapor deposition, pulsed laser deposition and spray-pyrolysis ${ }^{13-19}$. The sonochemical method is a useful method for obtaining $\mathrm{ZnO}$ nanoparticles multilayer films because it is environmentally friendly and a single process ${ }^{20}$. Textile and dye industry wastes have seriously polluted the surrounding environment and are harmful to human ${ }^{21}$. Therefore, an effective and economical treatment for the removal of these organic dyes is an important issue in many countries ${ }^{22}$.

This paper reports the preparation of $\mathrm{ZnO}$ nanoparticles and $\mathrm{ZnO}$ nanoparticles multilayer films under ultrasonic irradiation. The aim of this study was to examine the photocatalytic effects of $\mathrm{ZnO}$ nanoparticles multilayer films. The photocatalytic degradation of organic dyes, such as methylene blue, methyl orange and rhodamine $\mathrm{B}$, was examined under ultraviolet light at $254 \mathrm{~nm}$ using a UV-visible spectrophotometer.

\section{EXPERIMENTAL}

$\mathrm{Zn}\left(\mathrm{NO}_{3}\right)_{2} \cdot 6 \mathrm{H}_{2} \mathrm{O}, \mathrm{NaOH}, 35 \% \mathrm{H}_{2} \mathrm{O}_{2}$ solution, ethanol, isopropanol and $\mathrm{H}_{2} \mathrm{SO}_{4}$ were obtained from Samchun Chemicals. The organic dyes such as methylene blue (MB), methyl orange (MO) and rhodamine $\mathrm{B}(\mathrm{RhB})$ and (3-mercaptopropyl)-trimethoxysilane were purchased from Sigma-Aldrich. The glass slide was supplied by Fisher Scientific.

The synthesized $\mathrm{ZnO}$ nanoparticles morphology and crystallite size were analyzed by transmission electron microscopy (TEM, JEOL Ltd, JEM-2010) at an acceleration voltage of $200 \mathrm{kV}$. The surface of synthesized $\mathrm{ZnO}$ nanoparticles was examined by scanning electron microscopy (SEM, JEOL Ltd, JSM-6510) at an acceleration voltage of 0.5 to $30 \mathrm{kV}$. The structure of synthesized $\mathrm{ZnO}$ nanoparticles was characterized by X-ray diffraction (XRD, Bruker, D8 Advance). UV-visible spectroscopy of the samples was performed using an UVvisible spectrophotometer (Shimazu, UV-1601 PC). Ultrasonic 
irradiation of all samples was conducted in continuous mode using an ultrasonic generator UGI1200 (Hanil Ultrasonic Co., Ltd.) with a frequency $20 \mathrm{KHz}$ and nominal power of $750 \mathrm{~W}$. The ultrasonic generator was a horn type system with a $13 \mathrm{~mm}$ horn tip. An UV lamp (8 W, 254 nm, 77202 Marne La Valeecedex 1 France) was used as the ultraviolet light irradiation source.

Preparation of $\mathrm{ZnO}$ nanoparticles under ultrasonic irradiation: $1 \mathrm{MZn}\left(\mathrm{NO}_{3}\right)_{2} \cdot 6 \mathrm{H}_{2} \mathrm{O}$ and $10 \mathrm{M} \mathrm{NaOH}$ were dissolved separately in $6 \mathrm{~mL}$ of distilled water. Each solution was added to $15 \mathrm{~mL}$ ethanol. Two solutions were mixed in a 100 $\mathrm{mL}$ beaker and stirred vigorously for $45 \mathrm{~min}$. This mixture solution was reacted under ultrasonic irradiation for $45 \mathrm{~min}$ at room temperature. After the reaction was complete, the white precipitate was washed 5 times with ethanol.

Preparation of self-assembled $\mathrm{ZnO}$ nanoparticles multilayer films: To prepare the functionalized glass slide, the glass slide (size; $40 \mathrm{~mm} \times 10 \mathrm{~mm}$ ) was cleaned with a piranha solution $\left(2: 1(\mathrm{v} / \mathrm{v}), \mathrm{H}_{2} \mathrm{SO}_{4} / \mathrm{H}_{2} \mathrm{O}_{2}\right)$. The glass slide was then washed with distilled water and placed in $100 \mathrm{~mL}$ of an isopropyl alcohol solution containing $1 \mathrm{~mL}$ of the (3-mercaptopropyl)trimethoxysilane and $1 \mathrm{~mL}$ of distilled water. After this process, the solution which was contained glass slide was heated for $0.5 \mathrm{~h}$, the glass slide was washed with ethanol, blow dried with $\mathrm{N}_{2}$ and placed in an oven at $100{ }^{\circ} \mathrm{C}$ for $0.5 \mathrm{~h}$. The above process was repeated more than twice. The functionalized glass slide was placed in a vial containing $20 \mathrm{~mL}$ of an aqueous $\mathrm{ZnO}$ nanoparticles solution. The vial was reacted in the ultrasonic irradiation device at $20 \mathrm{~min}$ intervals. The procedure was repeated five times to form the five layer $\mathrm{ZnO}$ nanoparticles multilayer films.

Evaluation of the photocatalytic activity of $\mathrm{ZnO}$ nanoparticles multilayer films: The prepared $\mathrm{ZnO}$ nanoparticles multilayer films were used as a photocatalyst to test for the degradation of organic dyes, such as methylene blue, methyl orange and rhodamine $\mathrm{B}$. The prepared $\mathrm{ZnO}$ nanoparticles multilayer films were placed separately in a $20 \mathrm{~mL}$ vial containing $20 \mathrm{~mL}$ of the aqueous organic dye solution. Each vial was irradiated with a wavelength of $254 \mathrm{~nm}$ light using an UV-lamp. The degradation of the organic dyes by the photocatalyst was analyzed using a UV-visible spectrophotometer.

\section{RESULTS AND DISCUSSION}

The synthesized zinc oxide nanoparticles were dispersed in distilled water to determine the peak value of the zinc oxide nanoparticles. Fig. 1 showed the optical property of zinc oxide nanoparticles synthesized by the sonochemical method for $45 \mathrm{~min}$ at $\lambda_{\max }=360 \mathrm{~nm}$. The wavelength value of the peak of UV-visible spectrum of the synthesized zinc oxide nanoparticles was determined by the nature of electronic transition from the top of the valence band to the bottom of the conduction band and by particle size distribution and band gap distribution ${ }^{23,24}$. Also, the shape of the absorption edge depends upon the distribution of particles band gap and particles size. It means that the absorption edge showed to be narrow, which verified the formation of monodispersed zinc oxide nanoparticles by ultrasonic irradiation ${ }^{25}$.

Fig. 2 showed the XRD patterns of the zinc oxide nanoparticles synthesized by the sonochemical method for $45 \mathrm{~min}$.

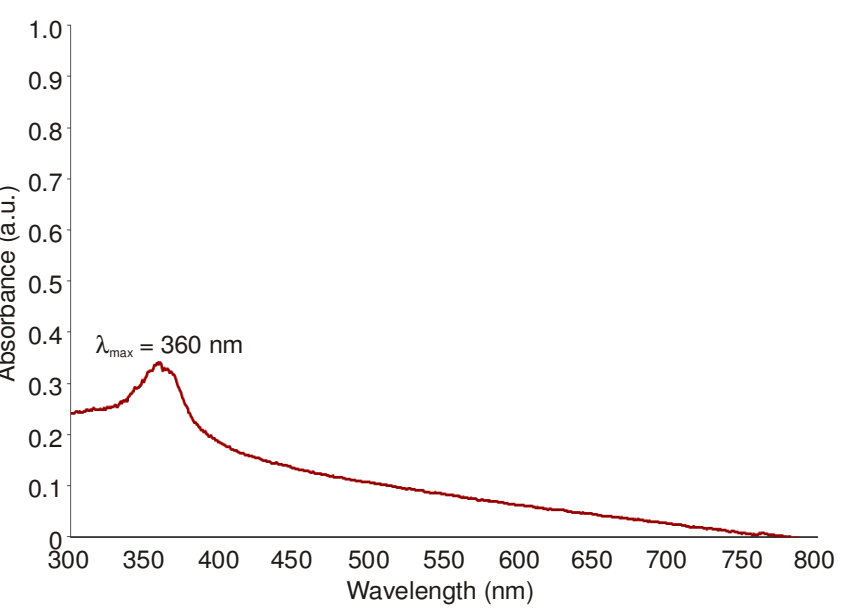

Fig. 1. UV-visible spectrum of the synthesized zinc oxide nanoparticles

The crystal structure of the synthesized zinc oxide nanoparticles was examined by XRD with $\operatorname{CuK} \alpha(\lambda=1.5406 \AA)$ radiation. The characteristic peaks of the synthesized zinc oxide nanoparticles were observed at $31.78^{\circ}, 34.42^{\circ}, 36.19^{\circ}, 47.60^{\circ}$, $56.53^{\circ}, 62.90^{\circ}, 66.40^{\circ}, 67.94^{\circ} 69.10^{\circ}, 72.50^{\circ}$ and $77.03^{\circ}$ as a $2 \theta$ value and marked index [(100), (002), (101), (102), (110), (103), (200), (112), (201), (004), (002)]. And the synthesized zinc oxide nanoparticles were observed to be highly crystalline and had the hexagonal type structure ${ }^{3}$.

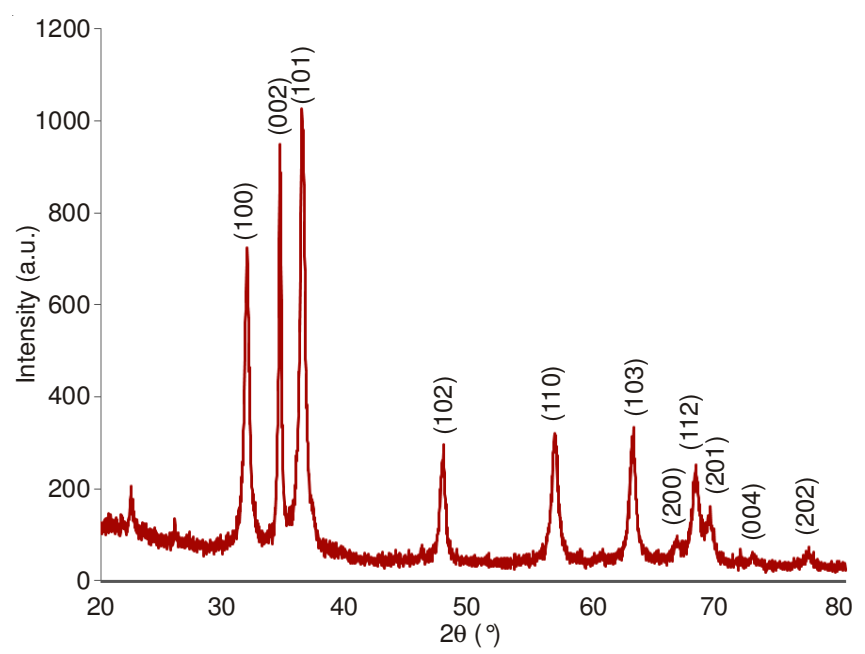

Fig. 2. XRD pattern of the synthesized zinc oxide nanoparticles

Fig. 3 showed a TEM image of the zinc oxide nanoparticles synthesized by the sonochemical method for $45 \mathrm{~min}$. The synthesized zinc oxide nanoparticles had a triangle, rod and spherical-like shape. The mean size of the synthesized zinc oxide nanoparticles was 40-70 nm.

Fig. 4 showed a SEM image of the zinc oxide nanoparticles synthesized by the sonochemical method for $45 \mathrm{~min}$. The synthesized zinc oxide nanoparticles were a finely agglomerated condition. The surface of the synthesized zinc oxide nanoparticles showed a snow flower-like shape with overlapping needles.

Fig. 5 showed the UV-visible spectra of the self-assembled zinc oxide nanoparticles multilayer films based on times. The optical properties of the self-assembled zinc oxide nanoparticles multilayer films was observed at $\lambda_{\max }=360 \mathrm{~nm}$ and was 


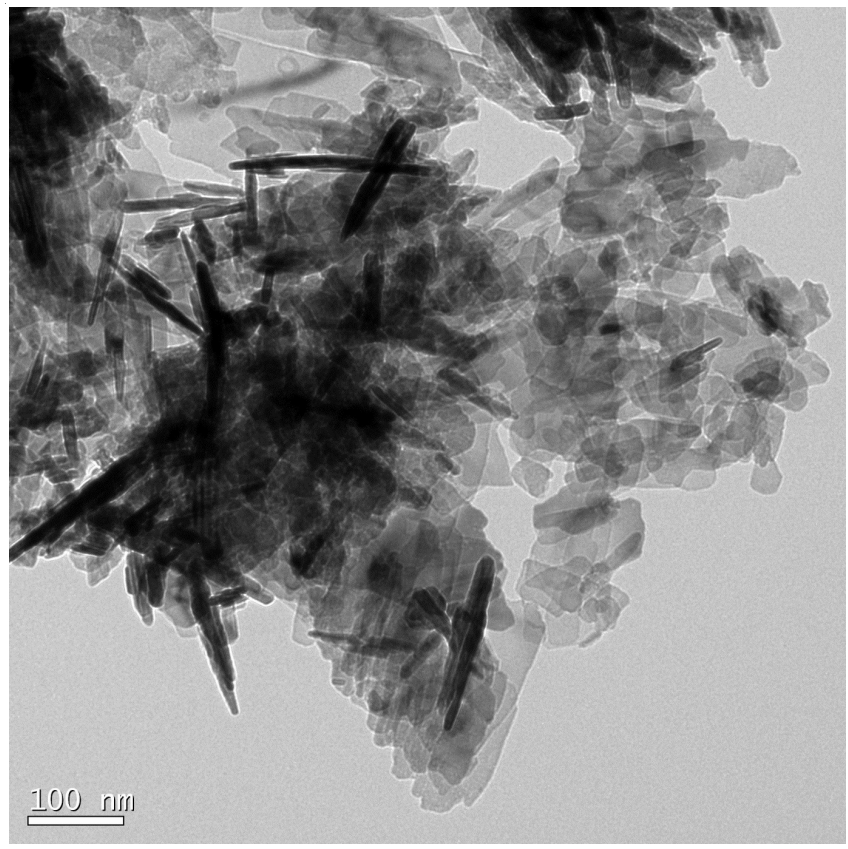

Fig. 3. TEM image of the synthesized zinc oxide nanoparticles

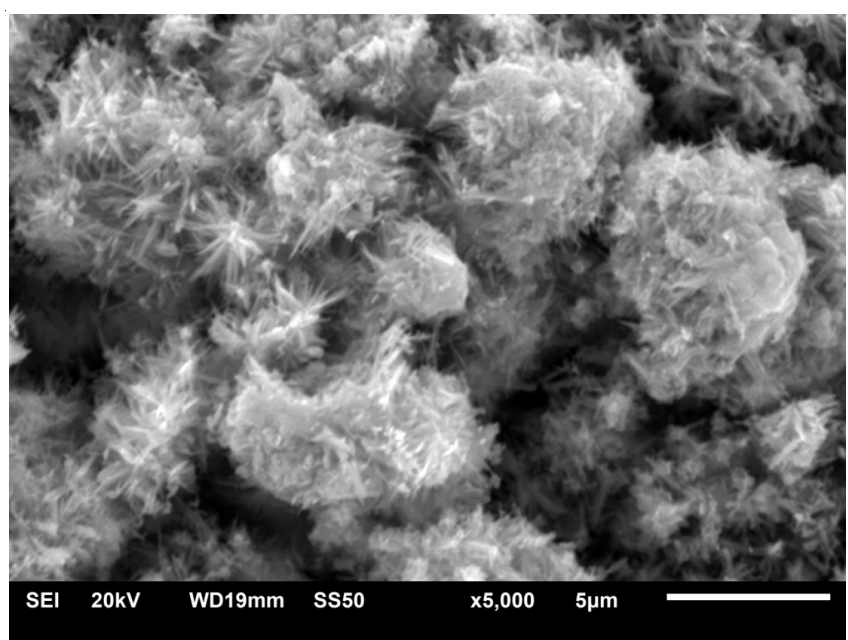

Fig. 4. SEM image of the synthesized zinc oxide nanoparticles

equal to the synthesized zinc oxide nanoparticles. As the reaction time increases, the absorbance of UV-visible spectra of zinc oxide nanoparticles multilayer films increased sequentially. Overall, a longer reaction time causes a stronger cohesion in the zinc oxide nanoparticles multilayer films. This explains

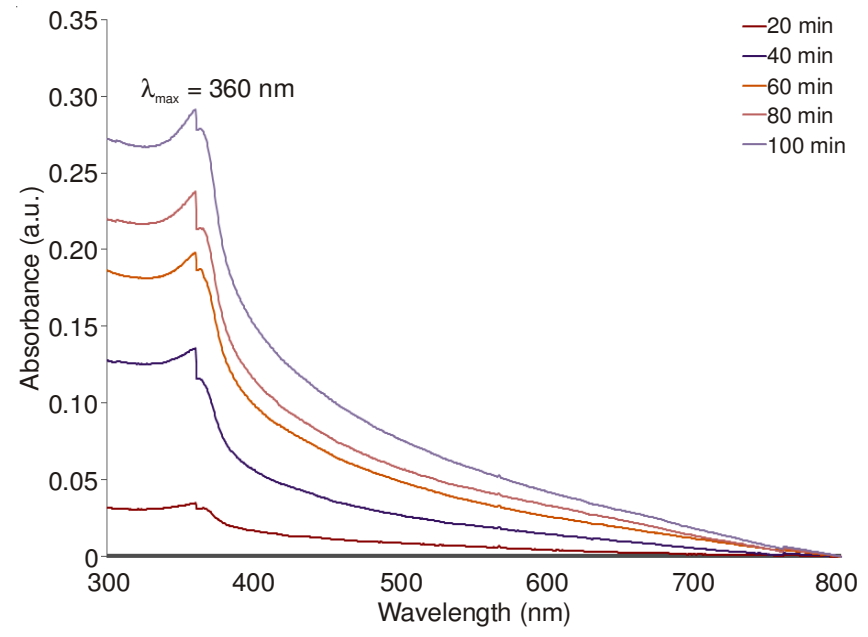

Fig. 5. UV-visible spectra of the self-assembled zinc oxide nanoparticles multilayer films under ultrasonic irradiation for the indicated time; $+20 \mathrm{~min},+20 \mathrm{~min},+20 \mathrm{~min},+20 \mathrm{~min}$ (from bottom to top)

alternately the continuous cohesion of zinc oxide nanoparticles due to the high density of zinc oxide nanoparticles on glass surface $^{25}$. The overall absorbance of UV-visible spectra was obtained from the layer-by-layer self assembly method under ultrasonic irradiation.

To confirm the photocatalytic performance, the organic dyes, such as methylene blue, methyl orange and rhodamine $\mathrm{B}$, were compared using a UV-visible spectrophotometer. Fig. 6 showed the UV-visible spectra of the degradation of (a) methylene blue, (b) methyl orange and (c) rhodamine B with the five layer zinc oxide nanoparticles multilayer films under ultraviolet irradiation at $254 \mathrm{~nm}$ for $5 \mathrm{~min}$. The photocatalytic performance was superior in methylene blue as compare to rhodamine B and methyl orange in the five layer zinc oxide nanoparticles multilayer films. The degradation of methyl orange and rhodamine B were almost similar. The order of effectiveness among the organic dyes degraded was methylene blue $>$ methyl orange $>$ rhodamine $\mathrm{B}$.

\section{Conclusion}

Zinc oxide nanoparticles were synthesized under ultrasonic irradiation. The $\mathrm{ZnO}$ nanoparticles showed a triangle, rod and spherical-like shape with a mean size of 40-70nm. The $\mathrm{ZnO}$ nanoparticles multilayer films were prepared under ultrasonic irradiation as a photocatalyst for the degradation of methylene blue, methyl orange and rhodamine B under
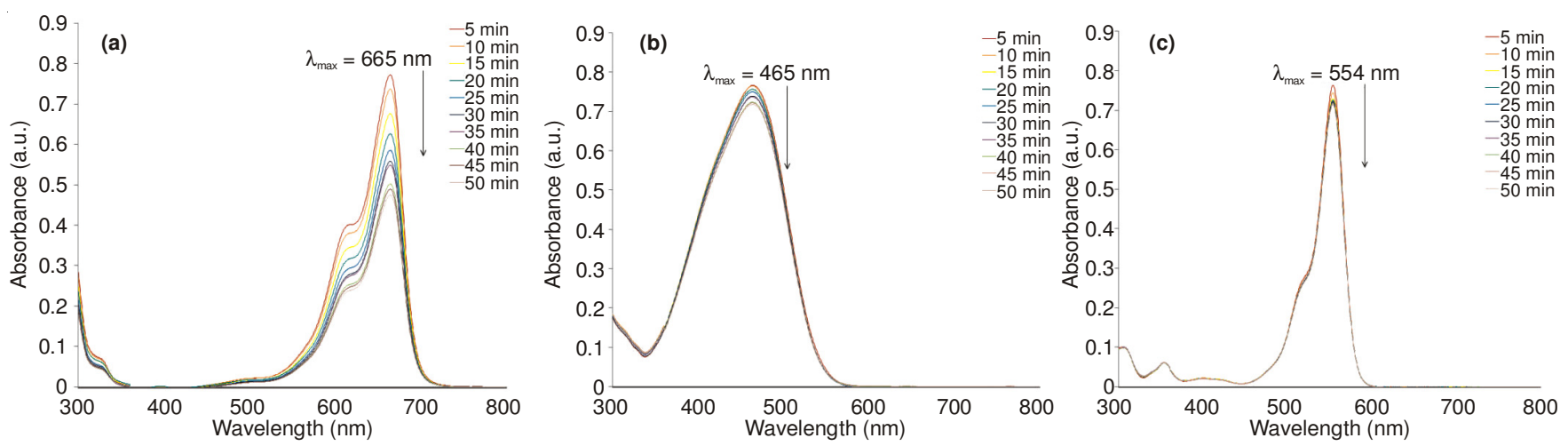

Fig. 6. UV-visible spectra of (a) methylene blue, (b) methyl orange and (c) rhodamine B degradation using zinc oxide nanoparticles multilayer films 
ultraviolet light at $254 \mathrm{~nm}$. Ultrasonic irradiation was found to be a good method for the cohesion of $\mathrm{ZnO}$ nanoparticles on the surface of the functionalized glass slide. The $\mathrm{ZnO}$ nanoparticles and $\mathrm{ZnO}$ nanoparticles multilayer films showed the same wavelength at $360 \mathrm{~nm}$. As the reaction time increased, the absorbance of the UV-visible spectra of the $\mathrm{ZnO}$ nanoparticles multilayer films increased sequentially. Among the organic dyes, such as methylene blue, methyl orange and rhodamine $\mathrm{B}$, the degradation of methylene blue was effective in the $\mathrm{ZnO}$ nanoparticles multilayer films as a photocatalyst under ultraviolet light at $254 \mathrm{~nm}$.

\section{ACKNOWLEDGEMENTS}

This study was supported by Sahmyook University funding in Korea.

\section{REFERENCES}

1. K. Siraj, K. Javaid, J.D. Pedarnig, M.A. Bodea and S. Naseem, J. Alloys Comp., 563, 280 (2013)

2. A.K. Srivastava, Mater. Lett., 62, 4296 (2008).

3. A.S. Lanje, S.J. Sharma, R.S. Ningthoujam, J.-S. Ahn and R.B. Pode, Adv. Powder Technol., 24, 331 (2013).

4. V.R. Shinde, T.P. Gujar, C.D. Lokhande, R.S. Mane and S.-H. Han, Mater. Sci. Eng. B, 137, 119 (2007).

5. V.R. Shinde, T.P. Gujar and C.D. Lokhande, Sol. Energy Mater. Sol. Cells, 91, 1055 (2007).

6. Y. Li, J. Gong and Y. Deng, Sens. Actuators A, 158, 176 (2010)
7. Z.L. Wang and J. Song, Science, 312, 242 (2006).

8. R. Nagaraja, N. Kottam, C.R. Girija and B.M. Nagabhushana, Powder Technol., 215-216, 91 (2012).

9. S. Sakthivel, B. Neppolian, M.V. Shankar, B. Arabindoo, M. Palanichamy and V. Murugesan, Sol. Energy Mater. Sol. Cells, 77, 65 (2003).

10. S. Gao, R. Cao and X. Li, Thin Solid Films, 500, 283 (2006).

11. L. Wang, N. Sakai, Y. Ebina, K. Takada and T. Sasaki, Chem. Mater., 17, 1352 (2005).

12. W.B. Ko, J.M. Yun, S.W. Jo and Y.S. Shon, Ultrasonics, 44, e363 (2006).

13. A. Kuroyanagi, Jpn. J. Appl. Phys., 28, 219 (1989).

14. Y. Zhang, B. Lin, Z. Fu, C. Liu and W. Han, Opt. Mater., 28, 1192 (2006).

15. J. Narayan, K. Dovidenko, A.K. Sharma and S. Oktyabrsky, J. Appl. Phys., 84, 2597 (1998).

16. B. Sang and M. Konagai, Jpn. J. Appl. Phys., 35(Part 2, No. 5B), L602 (1996).

17. Y. Natsume, H. Sakata and T. Hirayama, Phys. Status solidi A, 148, 485 (1995).

18. V. Craciun, J. Elders, J.G.E. Gardeniers and I.W. Boyd, Appl. Phys. Lett., 65, 2963 (1994)

19. J. De Merchant and M. Cocivera, Chem. Mater., 7, 1742 (1995).

20. K. Ghule, A.V. Ghule, B.J. Chen and Y.C. Ling, Green Chem., 8, 1034 (2006).

21. Q.I. Rahman, M. Ahmad, S.K. Misra and M. Lohani, Mater. Lett., 91, 170 (2013).

22. I. Fatimah, S. Wang and D. Wulandari, Appl. Clay Sci., 53, 553 (2011).

23. L. Wang and M. Muhammed, J. Mater. Chem., 9, 2871 (1999).

24. N.S. Pesika, K.J. Stebe and P.C. Searson, J. Phys. Chem. B, 107, 10412 (2003).

25. S.K. Hong, J.H. Lee, J.M. Kim, M.H. Kwon and W.B. Ko, J. Nanosci. Nanotechnol., 11, 593 (2011). 